\title{
Policy Analysis: BSN in 10
}

\author{
Joeanne Maljevac MHA,BSN,RN, BC, CCM and Shannon Olivieri MSN, RN-BC, CEN
}

Doctor of Nursing Practice,Sacred Heart University, USA

\section{Introduction}

An on-going cry for decades from nurse leaders is a standardization of entry level education for Registered Nurses (RNs). The Institute of Medicine (IOM) report in 2010 spurred the requirement for an increased pool of bachelor's prepared RNs by the year 2020 [1]. In a partnership with the Robert Wood Johnson Foundation (RWJF), the call was made by the IOM to augment the percentage of RNs with a baccalaureate degree to $80 \%[1,2]$. To align with the IOM recommendation, many states are in the process of developing "BSN in 10" legislation, however, New York State (NYS) was the first state to put this into law as Senate Bill S6768 [3]. This type of legislation mandates RNs with a diploma or associates degree to complete a bachelor's program within ten years of obtaining their initial license. This paper will address the need for highly educated nurses and policy developed called "BSN in 10", background into the Bachelor of Science in Nursing (BSN), developed policy, the stakeholders, driving political theory, and funding.

\section{Problem Identification}

Many large healthcare organizations already require baccalaureate or higher degree prepared RNs for positions of patient care. This is especially true in American Nurses Credentialing Center (ANCC) magnet-designated organizations where nurse leaders are required to hold a minimum of a baccalaureate degree, with a graduate degree preferred [4]. The country's largest work force of RNs, the Veteran's Administration (VA), requires a baccalaureate degree for RNs beyond an entry-level position. Along with the VA, the United States government mandates a BSN for active dutynurses. The interest has even moved beyond our own boarders to countries requiring a four-year degree and they include: Canada, Sweden, Portugal, Brazil, Iceland, Greece and the Philippines [4].

\section{BSN and Patient Outcomes}

Researchers started to focus on the role of the baccalaureate prepared nurse in the care of the acutely ill patient. In a study by Aiken, Clare, Cheung, Sloane and Silber (2003), patients attended by baccalaureate prepared RNs had greater outcomes of survival after surgery than patients in hospitals with a lower percentage of baccalaureate prepared RNs [5]. The Carnegie National Nursing Education Study revealed nursing administrators are concerned as nursing education is not able to meet the demands of evolving research and technology [6]. In a later study by Blegen, Goode,
*Corresponding author

Shannon Olivieri MSN, RN-BC, CEN, Doctor of Nursing Practice, Sacred Heart University, USA, E-Mail: olivieris@mail.sacredheart.edu

Submitted: 13 May 2018; Accepted: 20 May 2018; Published: 27 May 2018

Park, Vaughn,\& Spetz (2013), hospitals with a greater number of baccalaureate prepared RNs had a reduced incidence of patients with hospital acquired pressure ulcers, post-operative thrombus, and congestive heart failure complications [7].

\section{BSN and Professional Incentives}

Many positive results can be linked to an increased percentage of baccalaureate prepared RNs. As acute care hospitals are held to improved patient outcomes for reimbursement, the incentive for financial compensation for baccalaureate prepared RNs is vital. Historically, employers have not set a higher salary for baccalaureate prepared RNs at the entry level. However, as research is promoting the decreased patient morbidity and mortality, employers should be inclined to pay a better salary based upon education [8].

In addition to the problems of greater patient morbidity associated with health care facilities employing fewer baccalaureate prepared RNs, the differences in education levels in training has been a cause for concern. As most states only require a candidate to complete coursework approved by the National League of Nurses (NLN) to sit for the state licensing examination, the educational degree is of no consequence [9]. Historically, only a license was a pre-requisite for direct patient care roles rather than an education level [10]. While only an RN license is necessitated for entry level patient care, very little financial incentive is offered for those RNs with a baccalaureate degree or higher.

\section{BSN and the Future}

Presently, no gauge has been established to measure the outcome of a baccalaureate requirement for RNs. Since NYS was the first to require RNs to obtain a baccalaureate degree within ten years of initial licensure, the ripple effects are just beginning. Although the literature, research, and organizations have touted the importance of baccalaureate trained RNs, the table top exercises will now be put into action. Employers will need to differentiate the compensation paid to nurses with different education levels. The role of the bedside nurse who is still in a ten-year grace period may change with the advent of additional baccalaureate prepared RNs. Clarke (2016) proposed a potential controversy may develop when education is preferred rather than skill [11]. In a five-year study reviewed by O'Brien, Knowlton, and Whichello (2018), as the ratio of BSN prepared nurses are increased, negative patient outcomes are decreased [12]. 
As other states create a BSN in 10 or similar legislation, the lasting impacts have yet to be determined. Presently no other states have similar legislation however as the goals of 2020 are rapidly approaching, other states may soon propel a BSN requirement. Healthcare facilities may not financially reward the degree required as many nurse leaders have anticipated. When the baccalaureate degree is considered the entry point for licensed RNs, starting salaries may remain at the current rate. While patient outcomes will most likely improve, additional financial compensation for baccalaureate prepared RNs may not follow. Spetz and Bates (2013) reported RNs with a baccalaureate pathway were compensated only slightly more than their associate degree counterparts [8]. Surveys have not been published on the potential decrease in available RNs when entry level degrees are made a requirement.

\section{Potential Issues}

Nurses come into practice at varying timesin their lives. Many nurses complete their training after their children are school-aged or older and therefore enter the profession half-way through their working career. According to the NLN (n.d.), $30 \%$ of nursing students in an Associates Degree in Nursing (ADN) program were over the age of 30 [9]. Others may have had their college studies interrupted and were unable to complete a baccalaureate degree, and instead opted for an associated program for their training. As females are the predominate gender in the nursing profession, some RNs may not have the financial means to complete a baccalaureate degree within a specified timeframe. With the legislative requirements posed, these nurses would only have a limited career to perform bedside care. While the NYS legislation addresses where RNs should be in ten years academically, the initial requirements for licensure remain the same. Current RNs and RN program students are not affected [3].

Special interest groups have raised the awareness of the importance for baccalaureate prepared RNs. No documentation exists of patients requesting different levels of training for a bedside nurse. Rather, perceived difference of the training involved appear to be catalyst for increasing the number of baccalaureate prepared nurses. Although physician groups may support this type of legislation, little support in the literaturechampionsthis cause. This may seem like a win-win proposal, but the additional requirement may increase the nursing shortage rate. Altmann (2011) cited a decreased motivation for returning to higher education during times of economic instability [13].

\section{Objectives}

The interesting fact about legislation is, rarely do the authors have to enact it. The bill addressed issues such as expanding the preparation required for continued professional nursing licensure. The authors of the legislation addressed the role RNs have with other disciplines on the patient care team. They recognized the significance of maintaining a technically competent nursing care delivery model. Although NYS is the first to pass this legislation to improve patient care, other states are viewing the results closely[3].

\section{Background}

To get a full understanding the BSN in 10 legislation, a historical perspective must be taken. Fundamental education of nursing started with a diploma licensure in 1873, a BSN degree in 1916, and the ADN in 1952 [10]. IOM and ANCC Magnet Recognition Program strongly recommend the minimum education for RNs is a $\mathrm{BSN}$, but despite this recommendation there remains three different entry points into the profession [10]. "According to the 2013 National Workforce Survey of Registered Nurses, $18 \%$ of the current nursing workforce entered RN practice with a diploma, 39\% with an ADN, and 34\% with a BSN" [10]. In 2015, the National Workforce Survey of Registered Nurses noted that $14.3 \%$ of the current nursing workforce entered $\mathrm{RN}$ practice with a diploma, 38.5\% with an ADN, and 39\% with a BSN [14]. This show a decrease in diploma entry level into practice, approximately the same ADN percentage, and an increase in BSN-prepared RNs entry into practice.

\section{Social-Cultural}

According to the 2015 National Workforce Survey, about $80 \%$ of RNs identify as White/Caucasian, and about $20 \%$ as race/ethnicity other than White/Caucasian; this is an increase from the previous survey conducted in 2013 [14, 15]. While on the right track with IOM's recommendations to increased diversity, there is still a large gap in diversity in the workforce. The ADN programs allow for a population that has higher diversity, lower income, and decreased access to higher level education [10]. By removing barriers, more potential candidates can choose nursing as a profession. Requiring additional education requirements consequently can discourage future nursing school applicants.

\section{Economic}

The economics surrounding the BSN in 10 are multi-faceted. There is a positive correlationnoted between patient outcomes and percentage of BSN level RNs $[14,16]$. This has an impact on healthcare spending, with less monies needed to go toward the management of 30-day mortality, Hospital Acquired Pressure Ulcers (HAPU), postoperative deep venous thrombosis (DVT)/pulmonary embolus $(\mathrm{PE})$, failure to rescue and congestive heart failure (CHF) mortality. The cost of obtaining a BSN correlates with a higher out-of-pocket cost to the individual, which can be a deterrent. Many organizations offer tuition reimbursement, which may help to offset costs of obtaining a BSN, which makes the BSN in 10 a more realistic option than the BSN as singular entry point into the profession.

\section{Ethical}

Some individuals would like to see a differential in notoriety of various degrees in practice. The ADN and BSN nurse both hold the same title RN, and many professionals feel this is unfair and unethical. Passing the nursing licensure examination has been the standard and should still be the barometer for RN standards. Clinical skills can be obtained at the bedside and during tenure. Not all nurses aspire to management roles or advanced practice. If the BSN is the standard for nursing, what role will the licensed practical nurse have in patient care?

\section{Political}

IOM and ANA, and ANCC Magnet are large political figures in the profession and widely support the BSN-prepared professional. In 1965, the American Nursing Association (ANA) took the position a BSN should be an entry level minimum for RNs into practice; shortly after this position four states were chosen to be focus states as early implementers of the BSN entry level to practice [17]. The four states chosen were: Oregon, South Dakota, Montana, and Maine. In 1986, House Bill 1460 was fully instituted and created the BSN as entry level for RNs into practice and two-year educational requirement for LPNs in North Dakota [17]. This decision was made after many years of battle between state legislature and nurses association groups. Each year after, from 1987 to 2001, a bill was introduced 
to modify the existing bill and remove the educational requirement of BSN to entry level [17]. The issue became so convoluted, that with the nursing shortage looming, a new policy was created. The BSN as entry level into practice was maintained from 1987-2003, until House Bill 1245 rescinded the former bill and reestablished the multilevel education entry into practice [17].

\section{Stakeholders}

It would be hard to argue the benefits of an education. The primary group to be on the receiving end of an educated RN staff would be the patients. This would include patients in all settings such as the acute hospital, long term care, and even the community. With the research and studies published, a well-educated nursing staff can only improve care and services. Baccalaureate prepared nurses have demonstrated an ability to assimilate science and judgment in their practice to improve care (Matthias, 2014).

Other healthcare providers may also realize the advantages of a baccalaureate prepared RN staff. Collaboration has become the standard in treatment plans and teams. Other clinicians such as therapists, social workers, and consulting physicians rely on the expertise of the bedside nurse. When that nurse has the education to address complex issues and can utilize critical thinking skills to enhance a patient's recovery, the entire group dynamic is changed. This is particularly true when other members of the healthcare team are educated at the masters or doctorate level.

Healthcare organizations will acquire additionally trained nurses who can transition into leadership roles in the institution. As delivery of health care is evolving and increasingly complex, the baccalaureate program focus on nursing leadership will be invaluable to organizations. Many recent graduates from baccalaureate programs feel more comfortable with evidence, research and data compared to associate level RNs [2].

Although the BSN in 10 legislation is a significant culture shift from the beginnings of formalized nurses training, very limited information has been circulated in the media of the new law. It was listed as a short paragraph in state nursing newsletters. One would be mildly curious why this legislation intended to improve care has not been widely reported in the press.

\section{Policy Theory}

The BSN in 10 bill has officially passed in NYS and is on track for multistate issuance. The nursing profession is unique with varying educational level entry points into practice. It has been the viewpoint of major interest groups such as ANA and IOM entry into practice for the Registered Nurse (RN) should be a minimum of a Bachelor's in Nursing Science (BSN). The ANA has held this view for over half a century; after a study done on the increasing complexities of the healthcare system that called for a higher level of education from RNs to meet these needs [17]. The BSN in 10 bill has found middle ground to stand on between parties that support the BSN as entry level into practice, and those who believe that multiple educational entry points are still acceptable for licensure of registered professional nurse.

Political empirical theory is based on quantitative factors that define and predict political behaviors (Porche, 2012). The Bill A01842, known as BSN in 10, is based on the need for higher educated nurses that drives better patient outcomes. Research has indicated that there is a positive correlation between hospitals that have higher ratios of BSN RNs and patient outcomes [7]. There is also a solid foundation of research that has determined that multilevel educational entry points have increased diversity in the profession of nursing and helped towards effort to alleviate the mounting nursing shortage [10].

\section{Funding}

The law recently passed in New York requiring RNs to possess a baccalaureate degree for licensure or within ten years of passing the state licensing examination does not attribute any funding for the State Board to publicize the new ruling. Since this legislation will be the benchmark for other states, it has garnered much publicity. The cost of notification of the ruling will not be covered by the legislature either. Many press releases have been written already and will continue to gain momentum when other similar bills are introduced.

As the current NYS legislation for a BSN in 10 does not address the additional cost for future licensed RNs to obtain the additional education, payment for these courses will need to be shouldered by the nurse. In recent decades. Physical Therapy, Occupational Therapy, and Social Work have also needed to return to school for advanced degrees. For most undergraduate degrees, students are eligible for federal grants. The advantage of grants is those monies do not need to be repaid after the student finishes his or her education. Another option for the cost of tuition would be guaranteed student loans. These loans are subsidized by the government. The loan amount is based upon the student (and parent) financial need along with the cost of the tuition. A third option to pay for the additional education requirements is scholarship application. Although scholarship applications are encouraged by financial aid officers, many of these monies are difficult to obtain. Sources of scholarships can be based upon employment, major, financial status, or even ethnic background. In addition to basic demographics, often a written essay is required.

Paying for additional education is a common benefit offered by many employers under the heading of tuition reimbursement. Each employer has a set of criteria such as reimbursement after the course is taken, a minimum of a grade point average or even continuing employment after the degree is obtained. The Health Resources and Services Administration has additional benefits for potential students in programs under loans for disadvantaged students, nursing student loans, and scholarships for disadvantaged students [18].

The big financial winners in the BSN in 10 legislation will most likely be the programs offering a four-year degree in nursing. Institutions once cast aside by students may become more appealing. Community and two-year colleges will find it necessary to partner with colleges and universities to matriculate courses completed for RNs to continue their education [19]. To educate the influx of continuing education students, additional faculty positions will need to be created. For years, nursing programs have experienced waiting lists for admission and this trend will be furthered. Additionally, as older nurse faculty reach retirement age, qualified nursing instructors will be at a premium [2]. This is important to consider for advanced practice nurses or those RNs considering education in as their career choice. Years of nursing experience in addition to nurse practice degrees for potential faculty will be vital to meet the demands of increased enrollment. 


\section{Conclusion}

The BSN degree was established in the early twentieth century as the second entry level into practice for RNs. In the mid-1900s the ADN was introduced and became the third entry level point for RNs to sit for the licensing examination. The ADN educational pathway was derived to produce technical nurses that would have more training and education than a practical or diploma nurse [10]. It can be argued that the ADN programs offer a more attainable education for those who have financial burdens and create a pool of more diverse RNs.

As early as the 1960's, the American Nursing Association (ANA) took a firm stance that the BSN degree was the preferred entry to practice, and North Dakota was the first state to hold this standard from 1986-2003 [17]. It was strongly opposed by state level nurses' associations, and in 2003 the law was overturned returning multieducational level entry into practice. The complexity of illnesses in patients and the necessity for highly educated RNs to navigate the needs and intricacies of the health care system continues to evolve. New York is the first state to sign the BSN in 10 into law. Originally presented to Governor Cuomo in 2012, it went back through congress, and ultimately was signed into effect in December 2017.

The BSN in 10 law does still provide the professional RN entry into practice with an $\mathrm{ADN}$, and time to achieve the BSN. This requirement is less stringent than a mandated BSN to entry-level and may have more success compared to the previous attempt in North Dakota. Many states are eagerly looking on to see the success of this newly implemented law, and many states including New Jersey and California are eager to follow suit.

\section{References}

1. Institute of Medicine of the National Academies (2010) The future of nursing: leading change, advancing health. Retrieved from: http://nacns.org/wp-content/uploads/2016/11/5-IOMReport.pdf.

2. Robert Wood Johnson Foundation. (2013). Charting nursing's future. Reports on Policies thatCan Transform Patient Care 21.

3. Assembly Bill A1842B. (2017). Retrieved from The New York State Senate: https://www.nysenate.gov/legislation/bills/2017/ a1842/amendment/b

4. American Nurses Credentialing Center. (n.d.). Retrieved from: https://www.nursingworld.org/organizational-programs/ magnet/eligibility-requirements

5. Aiken LH, Clarke SP, Cheung RB, Sloane DM, Silber JH (2003) Educational levels of hospital nurses and surgical patient mortality. Journal of American Medical Association 290: 1617-1623.

6. Benner P, Sutphen M, Leonard V, Day L (2009) Book highlights from educating nurses: A call for radical transformation. Carnegie/Jossye-Bass.

7. Blegen MA, Goode CJ, Park SH (2013) Baccalaureate education in nursing and patient outcomes. The Journal of Nursing Administration 43: 89-94. doi: 10.1097/ NNA.0b013e31827f2028.

8. Spetz J, Bates T (2013) Is a baccalaureate in nursing worth it? The return to education 2000-2008. Health Services Research 48: 1859-1878.doi:10.1111/1475-6773.12104.

9. National League for Nursing. Retrieved from: http://www.nln. org/newsroom/nursing-education- statistics/nursing-studentdemographics.
10. Matthias AD (2015) Making the case for differentiation of registered nurse practice: Historical perspectives meet contemporary efforts. Journal of Nursing Educationand Practice 5: 108-114. doi: 10.5430/jnep.v5n4p108.

11. Clarke SP (2017) The BSN entry into practice debate. Nursing Made Incredibly Easy 15: 6-8.

12. O'Brien, D., Knowlton, M., \& Whichello, R. (2018). Attention health care leaders: Literature review deems baccalaureate nurses improve patient outcomes. Nursing Education Perspectives. doi: 10.1097/01.NEP.0000000000000303

13. Altmann TK (2011) Registered nurses returning to school for a bachelors degree in nursing: Issues emerging from a metaanalysis of the research. Contemporary Nurse 2: 256-272. doi: 10.5172/conu.2011.256.

14. Budden J, Moulton P, Harper K, Brunell ML, Smiley R (2016) The 2015 national nursing workforce survey. Journal of Nursing Regulation 7: S1-S90. Retrieved from: https://www.ncsbn. org $/ 3669 . \mathrm{htm}$.

15. Covner CT, Djukic M, Jun J, Fletcher J, Fatehi FK, et al. (2017) Diversity and education of the nursing workforce 2006-2016. Nursing Outlook 1-8. doi: 10.1016/j.outlook.2017.09.002.

16. Haskins S, Pierson K (2016) The impact of the Bachelor of Science (BSN) degree on patient outcomes: A systematic review. Journal of Nursing Practice Applications \& Reviews of Research 6: 40-49. doi: 10.13178/jnparr.2016.0601.0705.

17. Smith T (2010) A policy perspective on the entry into practice issue. Online Journal of Issues in Nursing 15: 2. Retrieved from http://www.nursingworld.org.chamberlainuniversity.idm. oclc.org/oji.

18. Health Resources \& Services Administration. Retrieved from: https://www.hrsa.gov/about/ organization/bureaus/bhw/index. html.

19. American Association of Colleges of Nursing. (n.d.). The impact of education on nursing practice. Retrieved from: http://www. aacnnursing.org/News-Information/Fact-sheets/Impact-ofEducation.

Copyright: (C2018 Shannon Olivieri. This is an open-access article distributed under the terms of the Creative Commons Attribution License, which permits unrestricted use, distribution, and reproduction in any medium, provided the original author and source are credited. 